\title{
Analysis of Dynamic Stiffness of Bridge Cap-Pile System
}

\author{
Jinhui Chu $\mathbb{D}^{1},{ }^{1}$ Meng Ma ${ }^{\mathbb{D}},{ }^{1}$ and Jinbo Liu $^{2}$ \\ ${ }^{1}$ School of Civil Engineering, Beijing Jiaotong University, Beijing, China \\ ${ }^{2}$ Wuhan Metro Group Co., Ltd., Wuhan, China \\ Correspondence should be addressed to Meng Ma; mameng_02231250@163.com
}

Received 20 November 2017; Accepted 12 March 2018; Published 24 April 2018

Academic Editor: Francesco Franco

Copyright (C) 2018 Jinhui Chu et al. This is an open access article distributed under the Creative Commons Attribution License, which permits unrestricted use, distribution, and reproduction in any medium, provided the original work is properly cited.

\begin{abstract}
In order to investigate the applicability of dynamic stiffness for bridge cap-pile system, a laboratory test was performed. A numerical model was also built for this type of system. The impact load was applied on the cap top and the dynamic stiffness was analysed. Then, the effect of the effective friction area between pile and soil was also considered. Finally, the dynamic stiffness relationship between the single pile and the cap-pile system was also compared. The results show that the dynamic stiffness is a sensitive index and can well reflect the static characteristics of the pile at the elastic stage. There is a significant positive correlation between the vertical dynamic stiffness index and bearing capacity of the cap-pile system in the similar formation environment. For the cap-pile system with four piles, the dynamic stiffness is about four times as large as the single pile between 10 and $20 \mathrm{~Hz}$.
\end{abstract}

\section{Introduction}

The pile foundation is an important component to bear the upper structures, whose working condition directly affects the safety of the upper buildings or bridges. For existing bridges in service, it is very important to evaluate the capacity of railway bridge piles, especially when the train axial load or train speed needs to increase. Two different types of capacity are needed to distinguish: one is ultimate bearing capacity which is usually controlled by the pile strength and the other is service capacity which is usually controlled by the pile settlement. For most friction piles designed as railway bridge foundations, the service capacity is paid more attentions and is determined by the maximum settlement $S_{a}$ of the pile head [1]. Static load test (SLT) is a reliable method to evaluate bearing capacity of pile foundations [2]; nevertheless, SLT cannot be employed for testing existing bridge piles in service. Then, the dynamic measurement is a good choice to estimate the service capacity. The transient response method (TRM), also known as the mechanical mobility method, is a dynamic loading method for the pile inspection. It was proposed in the 1970s by Davis and Dumm [3]. The application of TRM in pile foundation test has been carried out by many researches. Rausche et al. [4] compared the pulse echo and TRM and recommended the analyses should be made in both the frequency and time domains. Tham et al. [5] analysed the transient response of single pile under vertical load in layered soil by using the quasilinear time domain boundary element method. By using dynamic test, both low-strain and highstrain testing have been widely used in the pile nondestructive examination [6-9]. The pile dynamic response under vertical loads was also analysed by using various dynamic interaction models [10-13].

TRM analyses both the velocity and force signals in the frequency domain. The velocity spectrum is divided by the force spectrum to determine the mobility or mechanical admittance spectrum [14], which helps provide more information than the traditional pulse echo method to identify defects near the top of the pile [15]. Some key information from the graph, such as the peak/mean mobility ratio, mobility, and damping, is widely used to evaluate the pile integrity and pile length [16-19]. Another important parameter from mobility spectrum is the dynamic stiffness. It is defined as the slope of the low frequency linear portion of the spectrum from the origin to the first peak. The dynamic stiffness $K_{d}$ can be calculated by

$$
K_{d}(f)=\frac{2 \pi f}{|V(f) / F(f)|},
$$


where $V(f)$ and $F(f)$ are the velocity and force signals in the frequency domain. The value of $K_{d}$ is sensitive to the stiffness of the pile shaft under compression. When the frequency approaches to $0(f \rightarrow 0)$, the value of the dynamic stiffness approaches to the static stiffness $\left(K_{d} \rightarrow K_{s}\right)$. In practice, however, the frequency of the dynamic impulse cannot be $0 \mathrm{~Hz}$. Therefore, a coefficient $\alpha$ is introduced here to describe the ratio between the dynamic and static stiffness: $\alpha=K_{d} / K_{s}$. Then, the pile allowable bearing capacity $Q$ can be estimated by

$$
Q=\frac{K_{d} S_{a}}{\alpha},
$$

where $S_{a}$ is a guideline value of the pile settlement. The coefficient $\alpha$ is a bridge between the dynamic test and static capacity estimation; however, it is an empirical value rather than a theoretical one. This capacity estimation method was proposed in China in 1980s [20] and used for pile capacity evaluation [21]. Liu and Ma [22] analysed the parameter sensitivity on single pile and found that a reasonable dynamic stiffness can be used as an alert value for pile capacity. Ma et al. [23] measured the dynamic stiffness for 680 bridge piles and found that an obvious positive correlation exits between the dynamic stiffness and bearing capacity of intact piles. Nevertheless, the existing researches did not consider the influences of pile cap or platform on dynamic stiffness. For a railway bridge with a cap-pile foundation, it was not clear whether the capacity estimation method can still be employed as the existence of the pile cap. Accordingly, in this paper, a laboratory test was performed to learn the dynamic stiffness of the cap-pile system. Then a numerical model was also built for this type of system.

\section{Laboratory Test}

In order to analyse the relationship between dynamic stiffness and capacity of cap-pile system, a laboratory test was designed. As we mainly care about the basic principle and characteristic of dynamic stiffness, the similarity theory was not considered here. The cap-pile model was made of plaster, and it was then embedded in a sand box. For each foundation, there were four piles under the cap. All the piles were designed as friction piles considering the pile-soil interaction. The length of pile was $0.7 \mathrm{~m}$ with a diameter of $0.075 \mathrm{~m}$. The schematic diagram of the model was shown in Figure 1.

The dynamic stiffness test was based on the impulse transient response method. The hand hammer was used to impact the cap top. Then, the responses were obtained by the acceleration sensors installed on the top of the cap, and the force curve is obtained by force sensors installed on the hand hammer. The velocity responses can be calculated by integration. The dynamic stiffness can be obtained by (1). In order to ease the wave reflection on the steel plate of the sand box, five polystyrene foam cushions with a thickness of $0.02 \mathrm{~m}$ were installed on the bottom and four sides of the sand box (Figure 2).

For friction piles, the pile capacity is strongly dependent on the effective friction area around the piles. Therefore, in this test, the effective friction area between piles and soil
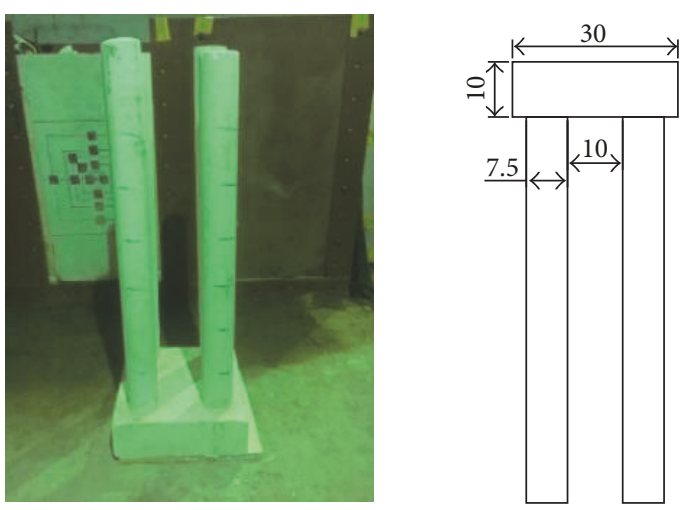

Figure 1: The picture and the dimension of cap-pile model (unit: $\mathrm{cm})$.

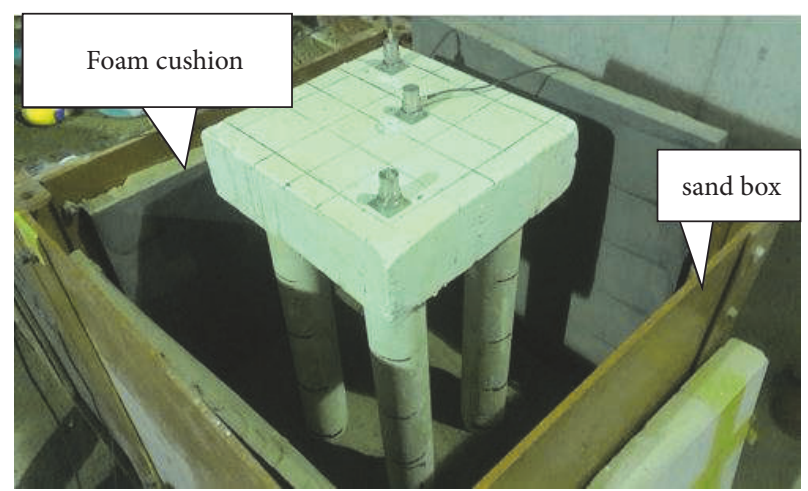

FIgURE 2: Laboratory test sand box.

was designed to decrease in order to model the reduction of capacity. Then, the relation between dynamic stiffness and effective friction area $A$ was analysed.

Suppose the initial embedded depth of piles was $H$, designed as $H=70 \mathrm{~cm}$, and the embedded depth decreased by $d=10 \mathrm{~cm}$ each time. In Figure 3, it can be found that, with the decrease of the embedded depth of the pile foundation, the value of $A$ was gradually reduced, and accordingly the bearing capacity of the system was also decreased. The dynamic stiffness as a function of frequency was shown in Figure 4.

It can be found that, with the decrease of $A$, dynamic stiffness decreases in all frequencies below $50 \mathrm{~Hz}$. In Figure 5(a), it can clearly show that $K_{d}$ decrease with $A$ at four different frequencies to be analysed: $5 \mathrm{~Hz}, 10 \mathrm{~Hz}, 15 \mathrm{~Hz}$, and $20 \mathrm{~Hz}$. The normalized dynamic stiffness by $H=70 \mathrm{~cm}$ or $A=$ $6597 \mathrm{~cm}^{2}$ was shown in Figure 5(b). At these frequencies, the general attenuation gradients of $K_{d}$ were similar overall but were different for each $A$. The normalized dynamic stiffness decayed largest with the value of $35 \%$ when the first layer of sand was relieved. When the subsequent soil layers were relieved, the normalized dynamic stiffness decayed gradually with the value of less than $10 \%$. That was the dynamic stiffness largely affected by the top soil. 
TABLE 1: Soil parameters.

\begin{tabular}{lccccc}
\hline Soil type & $H / \mathrm{m}$ & $\rho /(\mathrm{kg} / \mathrm{m} 3)$ & $c_{s} /(\mathrm{m} / \mathrm{s})$ & $c_{p} /(\mathrm{m} / \mathrm{s})$ & 285.5 \\
\hline Mucky soil & 15.0 & 1660.2 & 143.8 & 288.5 & 0.33 \\
Silt sand & 12.5 & 1850.0 & 145.3 & 333.6 & 0.33 \\
Fine sand & 10 & 1960.2 & 190.0 & 415.7 & 0.26 \\
Medium coarse sand & 7.5 & 1979.6 & 240.0 & 333.9 & 0.25 \\
Silty clay & 5.0 & 1929.6 & 181.6 & & 0.29 \\
\hline
\end{tabular}

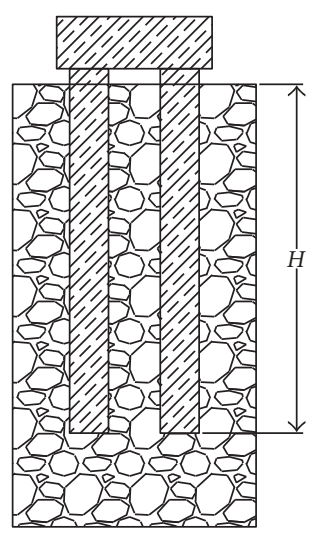

(a)

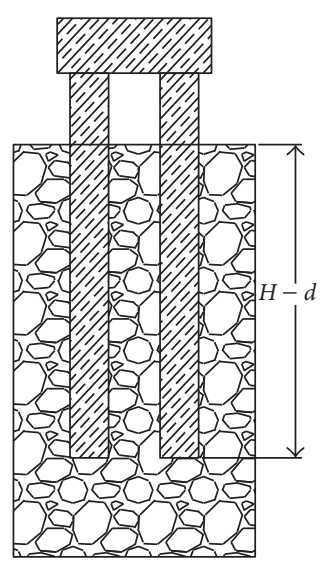

(b)

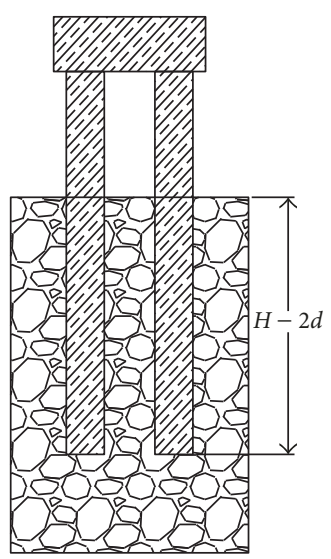

(c)

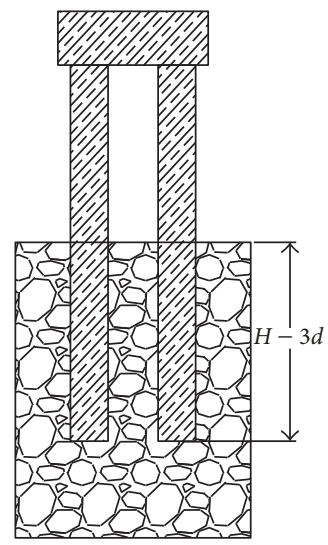

(d)

FIGURE 3: Sketch of decrease of the effective friction area between piles and soil. The embedded depth of piles was designed as (a) $H$, (b) $H-d$, (c) $H-2 d$, and (d) $H-3 d$.

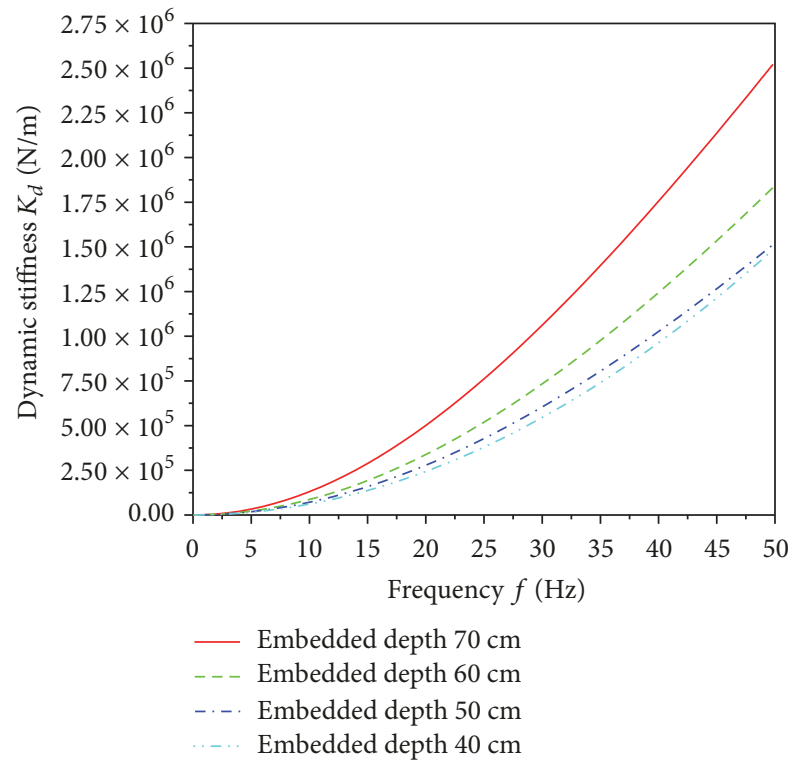

Figure 4: Amplitude frequency curve of dynamic stiffness at low frequency of centre of the cap.

\section{Numerical Analysis}

3.1. Finite Element Model. In this section, a 3D dynamic finite element (FE) model of cap-pile-soil was established for a bridge foundation (Figure 6). The dimensions of the piles and cap in the calculation are from a tram bridge. There were also four friction piles under the cap, the same as the model in the laboratory test. The length and the diameter of each pile were $15.5 \mathrm{~m}$ and $1.5 \mathrm{~m}$, respectively. The dimension of the cap was $6 \mathrm{~m} \times 6 \mathrm{~m} \times 2 \mathrm{~m}$. The centre distance between the four piles along the long side of cap was $3.5 \mathrm{~m}$. The concrete strength class was C25, whose modulus was $2.5 \times 10^{10} \mathrm{~Pa}$, the Poisson's ratio 0.16 , and the bulk density $2300 \mathrm{~kg} / \mathrm{m}^{3}$. According to the geological investigation report, the soil was simplified as five layers, and the detail parameters were listed in Table 1, where $H$ was the depth of the soil layer, $\rho$ the density, $c$ the cohesion, $\varphi$ the internal friction angle, $c_{s}$ and $c_{p}$ the S-wave and P-wave velocity and $v$ the Poisson's ratio.

The impact load was applied at the centre of the cap and the response at the cap $0.5 \mathrm{~m}$ away from the cap centre was analysed. The time history and Fourier spectrum of the dynamic load were shown in Figure 7. The Rayleigh damping assumption was employed. The damping matrix $\mathbf{C}$ is defined as a linear superposition of mass matrix $\mathbf{M}$ and stiffness matrix $\mathbf{K}$ with the coefficients $a_{1}$ and $a_{2}$. The two coefficients can be only defined by the damping ratio of soils and the analysis frequencies.

To avoid the wave reflection at the model boundaries, the artificial viscoelastic boundaries were applied, which were widely used together with FEM [24, 25]. Then, the surface springs were created at four side boundaries and the bottom boundary of the soil layers. The relationship between the spring stiffness and the elastic modulus $E$ can be estimated by an empirical formula: 


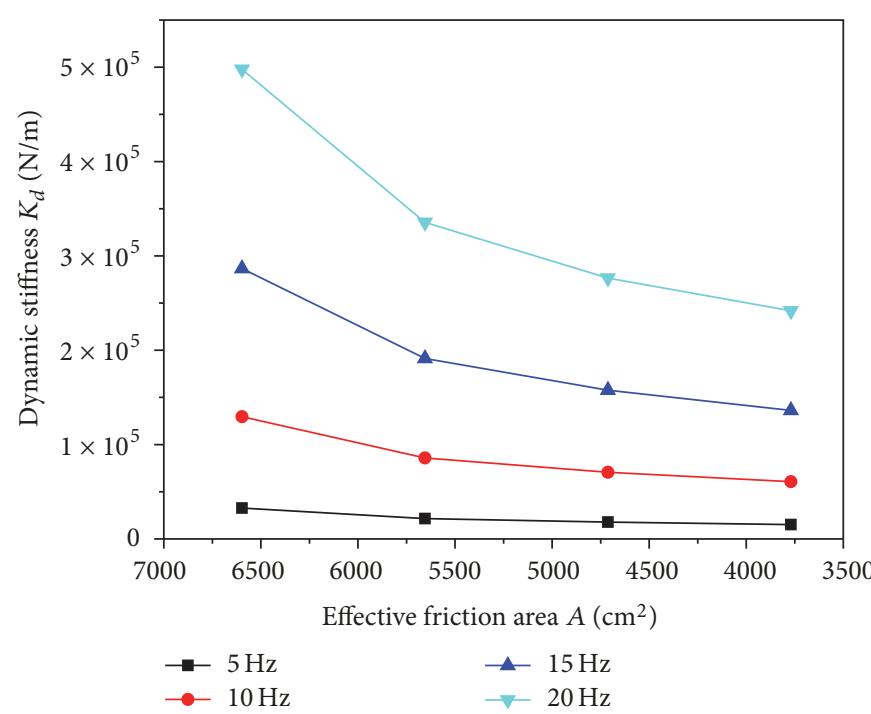

(a)

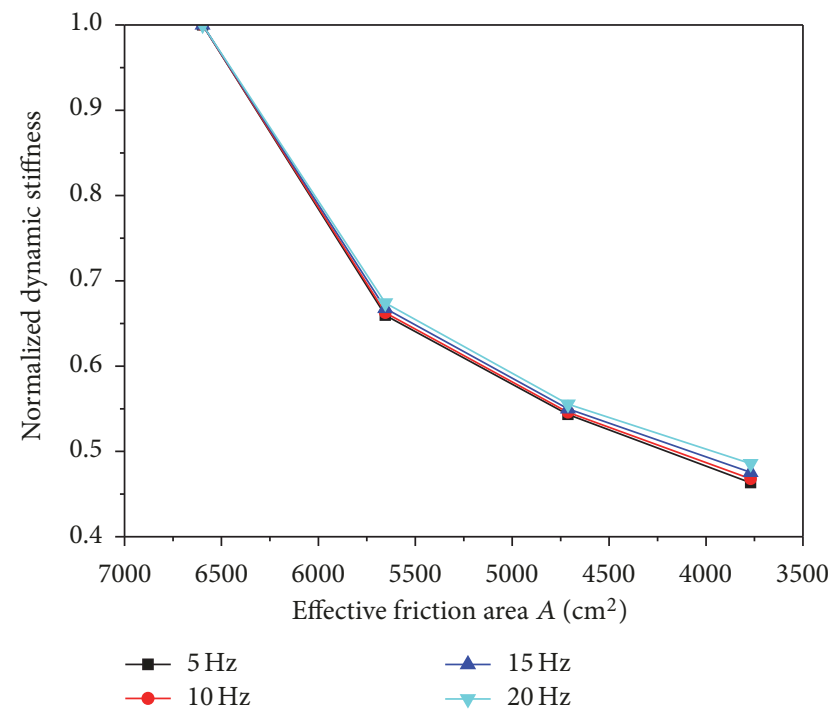

(b)

FIGURE 5: (a) Dynamic stiffness and (b) normalized dynamic stiffness change with effective friction area.
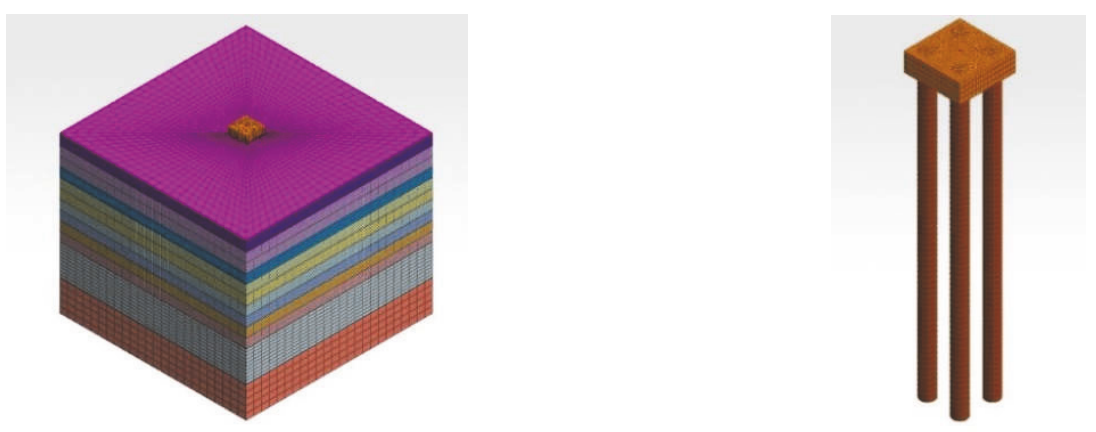

FIGURE 6: FE model of cap-pile-soil system.

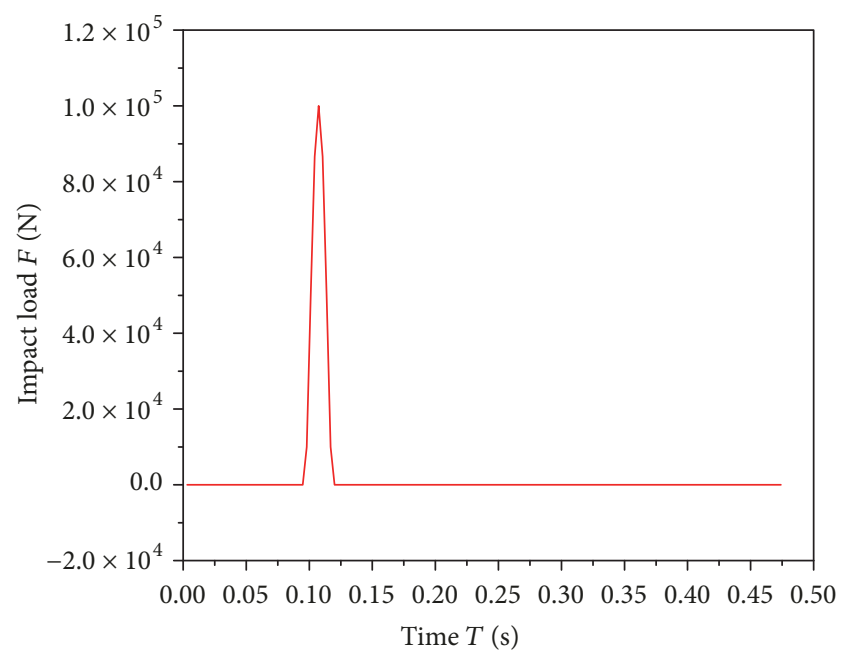

(a)

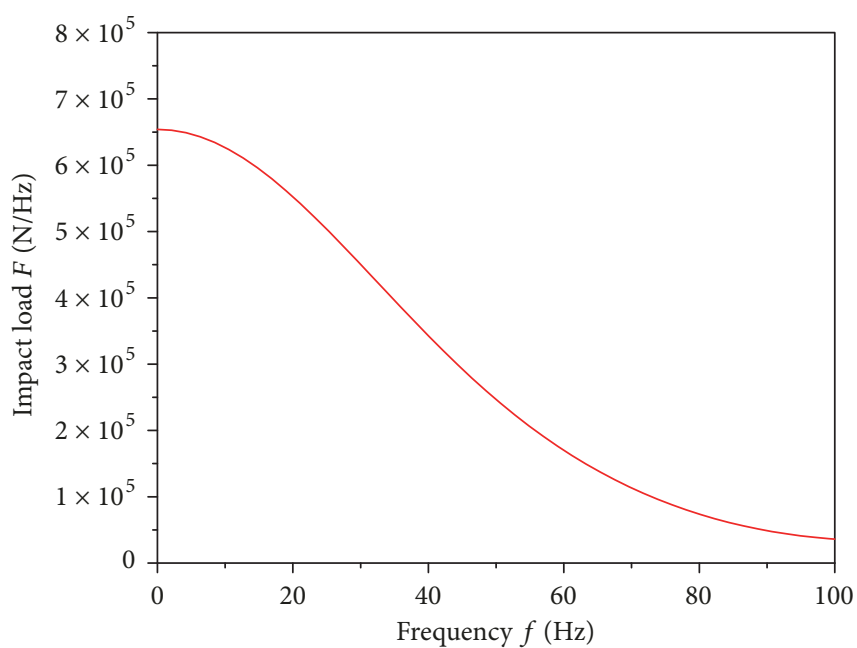

(b)

FIGURE 7: (a) Time history and (b) Fourier spectrum of the impact load. 


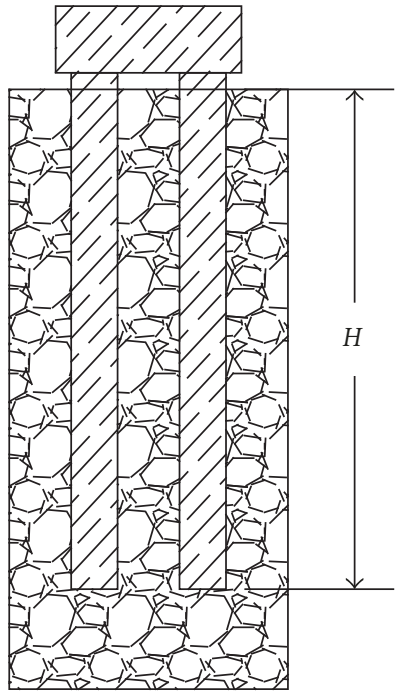

Concrete structure

Soil layer

(a) $H=15 \mathrm{~m}$

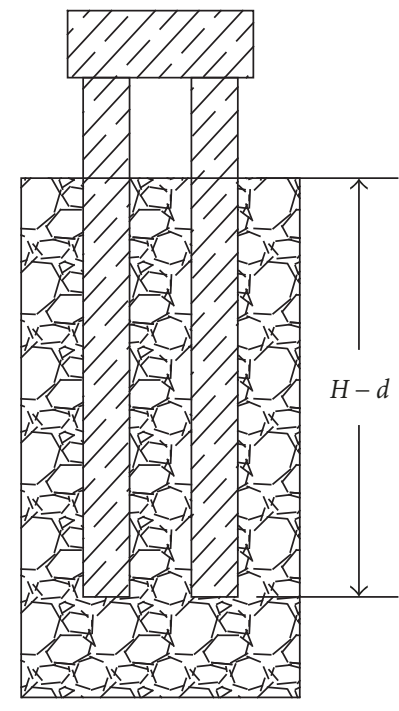

Concrete structure

Soil layer

(b) $H-d=12.5 \mathrm{~m}$

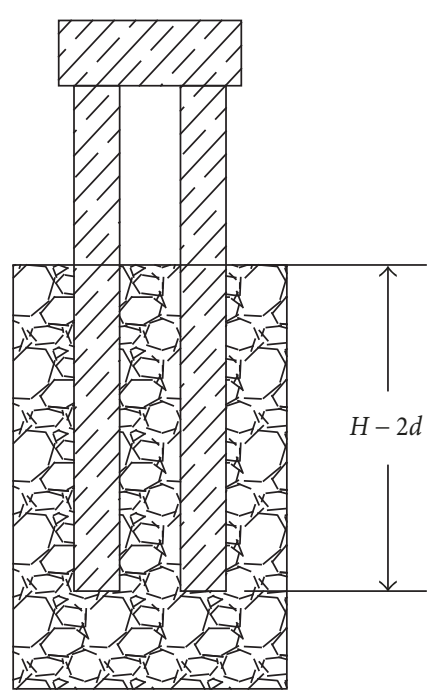

Concrete structure

Soil layer

(c) $H-2 d=10 \mathrm{~m}$

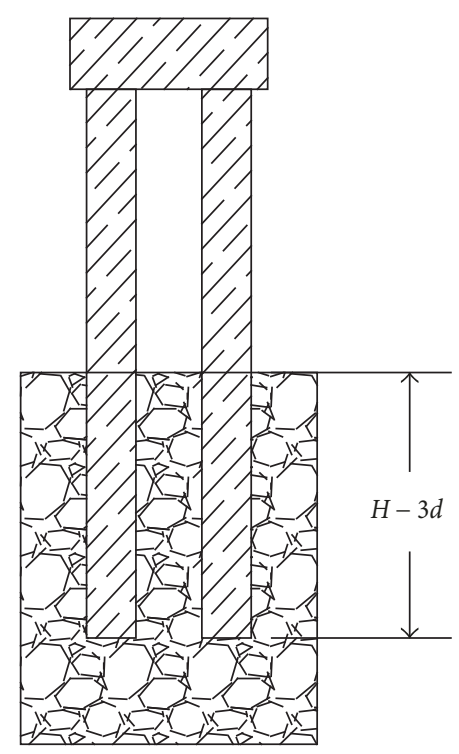

Concrete structure

Soil layer

(d) $H-3 d=7.5 \mathrm{~m}$

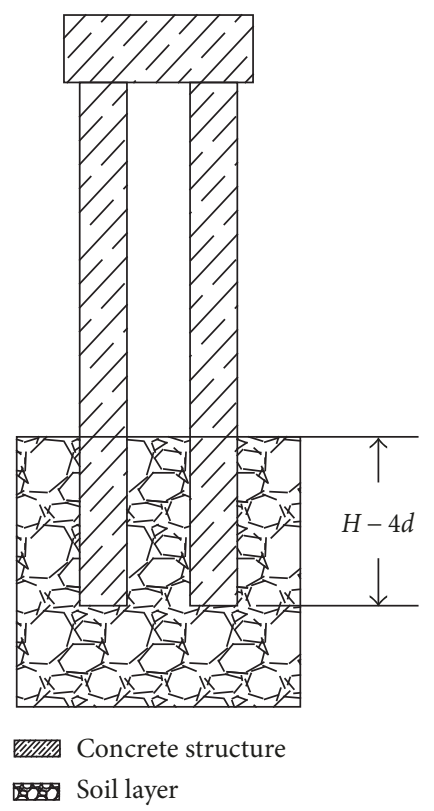

(e) $H-4 d=5 \mathrm{~m}$

FIGURE 8: Sketch of decrease of the effective friction area between piles and soil. The embedded depth of piles was designed as (a) $H$, (b) $H-d$, (c) $H-2 d$ (d) $H-3 d$, and (e) $H-4 d$.

$$
\begin{aligned}
& k_{v}=\frac{1}{30} E\left(\frac{\sqrt{A_{v}}}{30}\right)^{-3 / 4}, \\
& k_{h}=\frac{1}{30} E\left(\frac{\sqrt{A_{h}}}{30}\right)^{-3 / 4},
\end{aligned}
$$

where $E$ is the elastic modulus; $A_{v}$ and $A_{h}$ are the crosssectional area in the normal and tangential directions at the boundaries.
3.2. Effect of Effective Friction Area. As the capacity of friction piles was strongly related to the effective friction area around the piles. Similar to Section 2, here in the FE model by changing the thickness of the soil around the pile foundation, the effective friction area was changed.

Suppose that the initial embedded depth of piles was $H$, designed as $H=15 \mathrm{~m}$, and the embedded depth decreased by $d=2.5 \mathrm{~m}$ each time (Figure 8 ).

Figure 9 shows the velocity admittance of the cap response. It can be found that, with the decrease of the 
TABLE 2: The pile and cap dimensions of the four FE models.

\begin{tabular}{lcccc}
\hline Pile and cap & M1 & M2 & M3 & M4 \\
\hline Pile & & & 1.5 & 1.5 \\
$\quad 1.5$ & 15.5 & 15.5 & 15.5 \\
$\quad$ Diameter/m & 15.5 & & & \\
$\quad$ Length $/ \mathrm{m}$ & & $2.5 \times 2.5 \times 2.0$ & $6.0 \times 2.5 \times 2.0$ & $6.0 \times 6.0 \times 2.0$ \\
\hline Cap & - & & & \\
$\quad$ Dimension: length $\times$ width $\times$ height $/(\mathrm{m} \times \mathrm{m} \times \mathrm{m})$ &
\end{tabular}

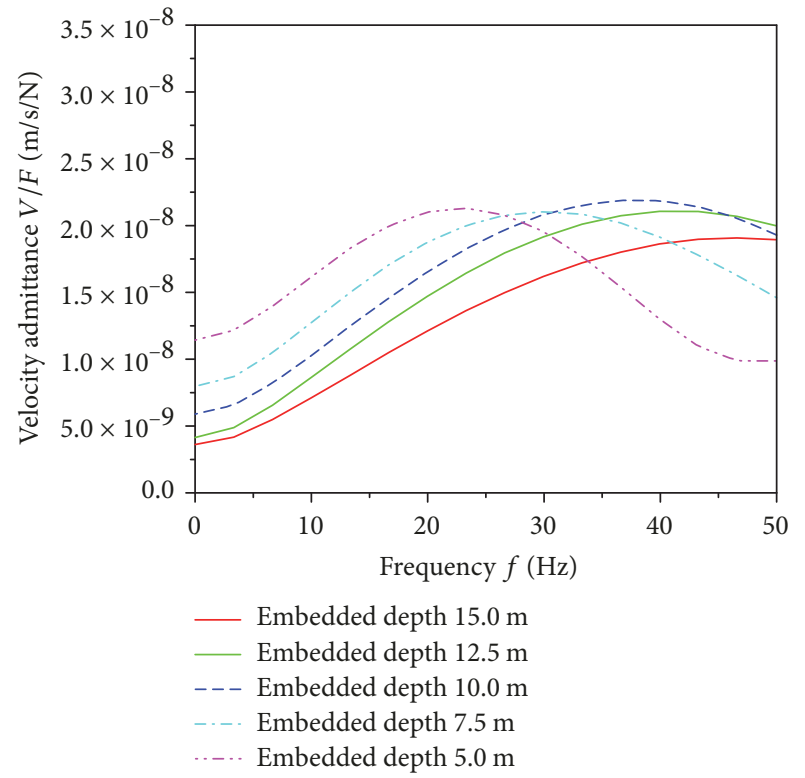

FIGURE 9: The time history and velocity admittance of the cap response.

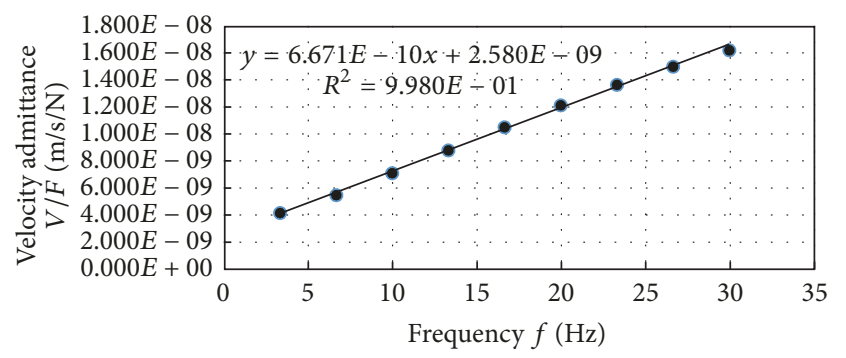

FIGURE 10: The linear fitting curve of low frequency curve of admittance curve.

effective friction area, the first natural frequency was also decreased. In the low frequency of the admittance curve, the linear regression analysis was carried out (Figure 10). It can be found that when the embedded depth of pile foundation was $15 \mathrm{~m}$, the slope of the linear fitting curve for the low frequency can be determined to be $k=6.671 \times 10^{-10} \mathrm{~N} / \mathrm{m}$. Then, the dynamic stiffness of the centre measuring point at the top of the cap can be calculated as $K_{d}=9.419 \times 10^{9} \mathrm{~N} / \mathrm{m}$.

In Figure 11, it can be clearly observed that the normalized dynamic stiffness by $H=15 \mathrm{~m}$ decayed with the effective

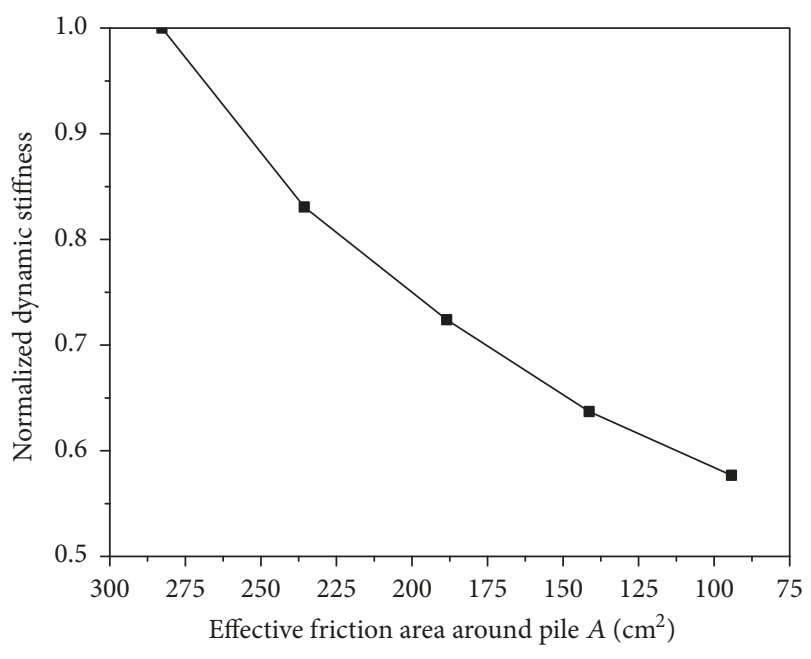

FIGURE 11: The normalized dynamic stiffness change with effective friction area.

friction area. The simulation result was similar to the test result in Section 2.

3.3. Comparison of Single Pile and Cap-Pile System. To analyse the dynamic stiffness relationship between the single pile and the cap-pile system, four FE models were built (M1 M4) (Figure 12). In M1, there was only single pile; in M2, a single pile with a small cap was built; in M3, two piles under the cap were considered; finally, in M4, a cap-pile system with four piles was built. The piles and cap dimensions were listed in Table 2

The impact load was applied at the centre of the cap (or pile in M1) and the responses on the cap head were analysed. The time history and Fourier spectrum of the dynamic load were shown in Figure 7 . The velocity admittance and dynamic stiffness curves of the four models were shown in Figure 13. It can be found that, in the frequencies below $30 \mathrm{~Hz}$, models M1 and M2 have similar values of dynamic stiffness. The existence of small cap induces the decrease of the value. Model M4 has the largest dynamic stiffness, which is about four times as large as M1 and M2 between 10 and $20 \mathrm{~Hz}$. Model M3 has the second largest dynamic stiffness, which is about twice as large as M1 and M2.

\section{Conclusion}

In order to analyse the dynamic stiffness of cap-pile system, both a laboratory test and numerical simulation were 


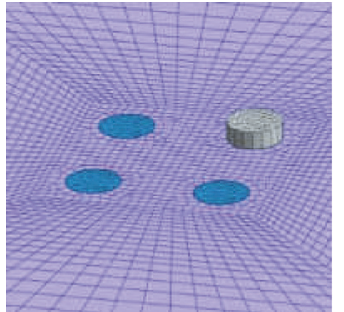

M1

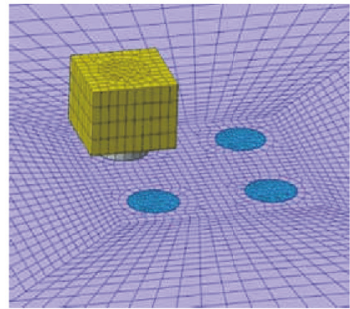

M2

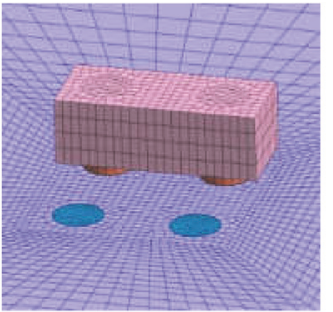

M3

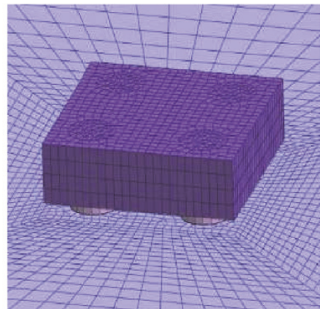

M4

FIGURE 12: FE models of the cap-pile-soil system.

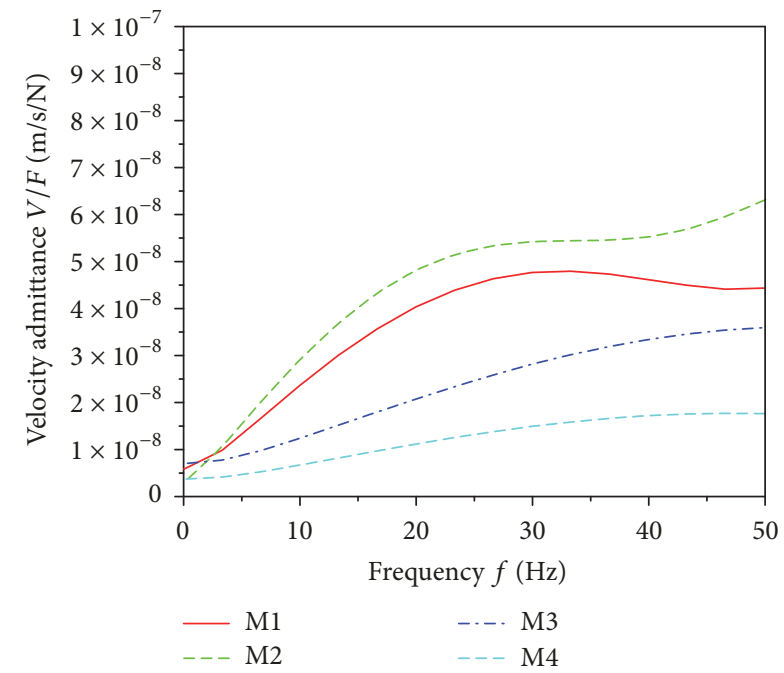

(a)

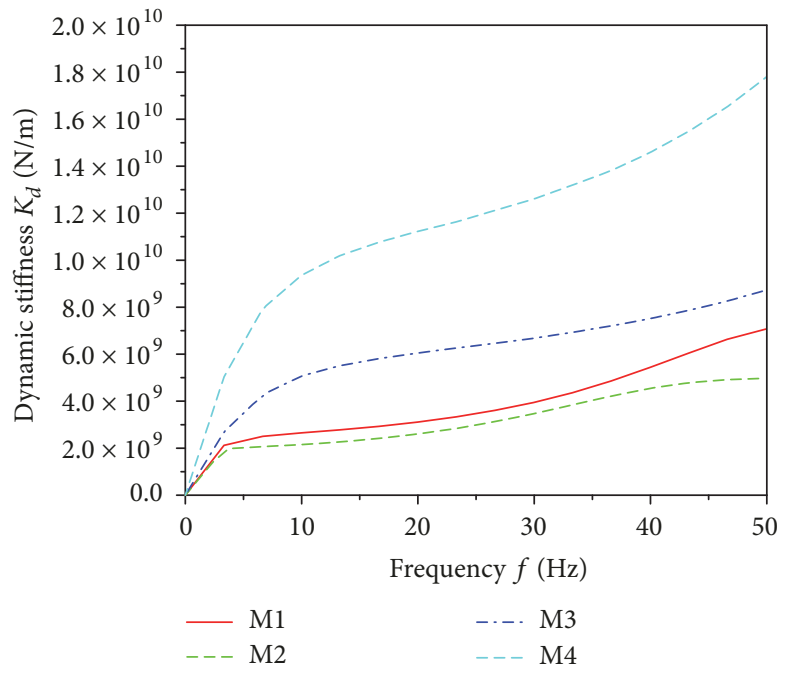

(b)

FIgURE 13: The (a) velocity admittance and (b) dynamics stiffness of four models.

performed in this paper. The results show that the dynamic stiffness obtained from the pile mobility curve is a sensitive index and can well reflect the static characteristics of the pile at the elastic stage. In addition, there is a significant positive correlation between the vertical dynamic stiffness index and bearing capacity of the cap-pile system in the similar formation environment. Finally, for the cap-pile system with four piles, the dynamic stiffness is about four times as large as the single pile between 10 and $20 \mathrm{~Hz}$.

\section{Conflicts of Interest}

The authors declare that they have no conflicts of interest.

\section{Acknowledgments}

The authors wish to acknowledge the support and motivation provided by the Fundamental Research Funds for the Central Universities (no. 2016JBM034) and the Funding of College Student Scientific Research and Training Projects of Beijing Jiaotong University (no. 160130044).

\section{References}

[1] K. Jozefiak, A. Zbiciak, M. Maslakowski, and T. Piotrowski, "Numerical modelling and bearing capacity analysis of pile foundation," in Proceedings of the 24th Russian-Polish-Slovak Seminar on Theoretical Foundation of Civil Engineering, TFoCE 2015, pp. 356-363, Russia, August 2015.

[2] G. S. Budi, M. Kosasi, and D. H. Wijaya, "Bearing capacity of pile foundations embedded in clays and sands layer predicted using PDA test and static load test," in Proceedings of the 5th Euro Asia Civil Engineering Forum Conference, EACEF 2015, pp. 406-410, Indonesia, September 2015.

[3] A. G. Davis and C. S. Dumm, "From theory to field experience with the non-destructive vibration testing, Proceeding of Institution of Civil Engineers," in Proceedings of the Part 2, vol. 2, no. 57, pp. 571-593, 1974.

[4] F. Rausche, S. Renkung, and G. E. Likins, "Comparison of pulse echo and transient response pile integrity test methods," Transportation Research Record, pp. 21-27, 1991.

[5] L. G. Tham, C. K. Chu, and Z. X. Lei, "Analysis of the transient response of vertically loaded single piles by time-domain BEM," Computers \& Geosciences, vol. 19, no. 2, pp. 117-136, 1996. 
[6] S.-H. Ni, L. Lehmann, J.-J. Charng, and K.-F. Lo, "Low-strain integrity testing of drilled piles with high slenderness ratio," Computers \& Geosciences, vol. 33, no. 6-7, pp. 283-293, 2006.

[7] J. Paquet and M. Briard, "Nondestructive quality control of concrete piles," Annales de lInstitut Technique du Batiment et des Travaux Publics, pp. 49-80, 1998.

[8] L. Yanlong, L. Shouyi, Y. Yang, and T. Xing, “Temperature stress and surface insulation measures of concrete face slabs during cold wave period," International Journal of Civil Engineering, vol. 13, no. 4, pp. 501-507, 2015.

[9] Y. Li, Y. Sun, B. Li, and Z. Xu, "Penalty function-based method for obtaining a reliability indicator of gravity dam stability," Computers \& Geosciences, vol. 81, pp. 19-25, 2017.

[10] W. B. Wu, K. H. Wang, Z. Q. Zhang, and C. J. Leo, "Soilpile interaction in the pile vertical vibration considering true three-dimensional wave effect of soil," International Journal for Numerical and Analytical Methods in Geomechanics, vol. 37, no. 17, pp. 2860-2876, 2013.

[11] M. F. Randolph and A. J. Deeks, "Dynamic and static soil models for axial response," in Proceedings of the in Proceedings of the 4th International Conference on the Application of stress wave Theory to Piles, pp. 3-14, The Hague, The Netherlands, September 1992.

[12] O. Michaelides, G. Gazetas, G. Bouckovalas, and E. Chrysikou, "Approximate non-linear dynamic axial response of piles," Géotechnique, vol. 48, no. 1, pp. 33-53, 1998.

[13] Y. Yesilce and H. H. Catal, "Free vibration of piles embedded in soil having different modulus of subgrade reaction," Applied Mathematical Modelling, vol. 32, no. 5, pp. 889-900, 2008.

[14] L. Liang and J. Beim, "Effect of soil resistance on the low strain mobility response of piles using impulse transient response method," in Proceedings of the in Proceedings of the 8th International Conference on the Application of Stress Wave Theory to Piles, pp. 435-441, Lisbon, Portugal, September 2008.

[15] F. Rausche, G. Likins, and M. H. Hussein, "Analysis of PostInstallation Dynamic Load Test Data for Capacity Evaluation of Deep Foundations," in Proceedings of the Symposium Honoring Dr. John H. Schmertmann for His Contributions to Civil Engineering at Research to Practice in Geotechnical Engineering Congress 2008, pp. 312-330, New Orleans, Louisiana, United States.

[16] A. G. Davis, "The nondestructive impulse response test in North America: 1985-2001," NDT \& E International, vol. 36, no. 4, pp. 185-193, 2003.

[17] S. T. Liao and J. M. Roesset, "Dynamic response of intact piles to impulse loads," International Journal for Numerical and Analytical Methods in Geomechanics, vol. 21, no. 4, pp. 255-275, 1997.

[18] K. F. Lo, S. H. Ni, and Y. H. Huang, "Non-destructive test for pile beneath bridge in the time, frequency, and time-frequency domains using transient loading," Nonlinear Dynamics, vol. 62, no. 1-2, pp. 349-360, 2010.

[19] N. Massoudi and W. Teffera, "Non-destructive testing of pile using the low strain integrity method," in Proceedings of the in Proceedings of the 5th International Conference on Case Histories in Geotechnical Engineering, New York, NY, USA, April 2004.

[20] Y. Z. Xu, "Determination of pile bearing capacity by dynamic test," Chinese Journal of Geotechnical Engineering, vol. 14, no. 1, pp. 74-83, 1992.

[21] C. T. Zheng, Y. Wang, S. J. Xu, and et al., "Pile bearing capacity measurement by steady mechanical impedance method," Water Resources and Hydropower Engineering, vol. 28, no. 8, pp. 50-52, 1997.
[22] J. Liu and M. Ma, "Analysis of the dynamic stiffness and bearing capacity for pile foundations," in Proceedings of the International Conference on Vibroengineering - 2015, pp. 134-139, chn, September 2015.

[23] M. Ma, J. Liu, Z. Ke, and Y. Gao, "Bearing Capacity Estimation of Bridge Piles Using the Impulse Transient Response Method," Shock and Vibration, vol. 2016, Article ID 4187026, 2016.

[24] Z. Wanming, H. Zhenxing, and S. Xiaolin, "Prediction of highspeed train induced ground vibration based on train-trackground system model," Earthquake Engineering and Engineering Vibration, vol. 9, no. 4, pp. 545-554, 2010.

[25] Q. Xu, Z. Xiao, T. Liu, P. Lou, and X. Song, "Comparison of 2D and $3 \mathrm{D}$ prediction models for environmental vibration induced by underground railway with two types of tracks," Computers \& Geosciences, vol. 68, pp. 169-183, 2015. 


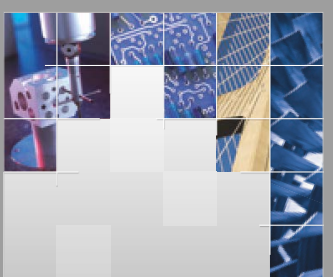

\section{Enfincering}
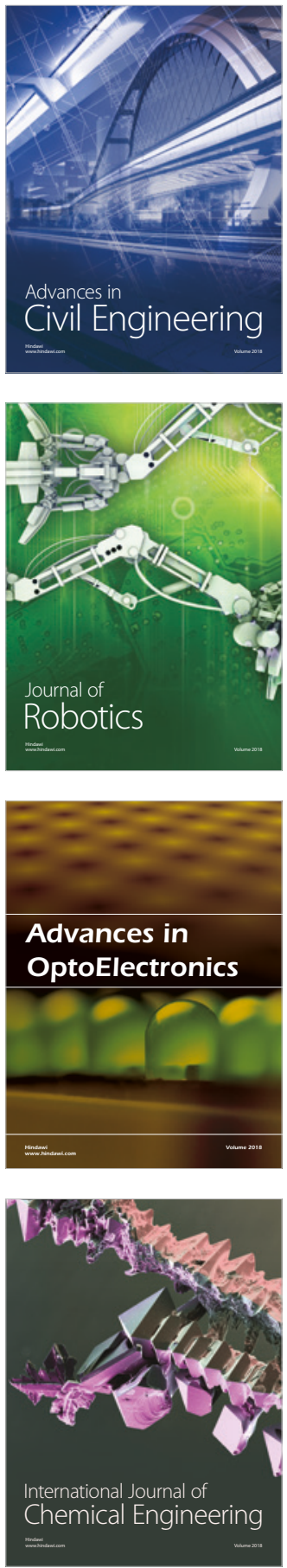

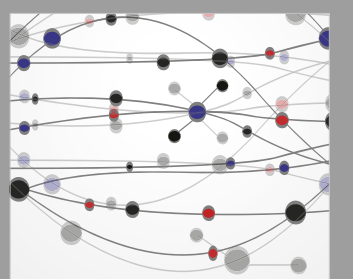

\section{Rotating \\ Machinery}

The Scientific World Journal

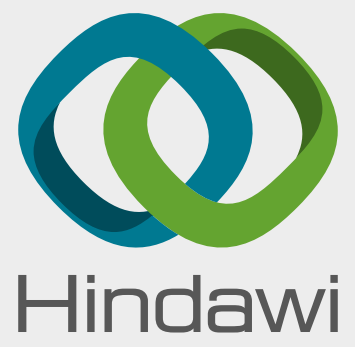

Submit your manuscripts at

www.hindawi.com
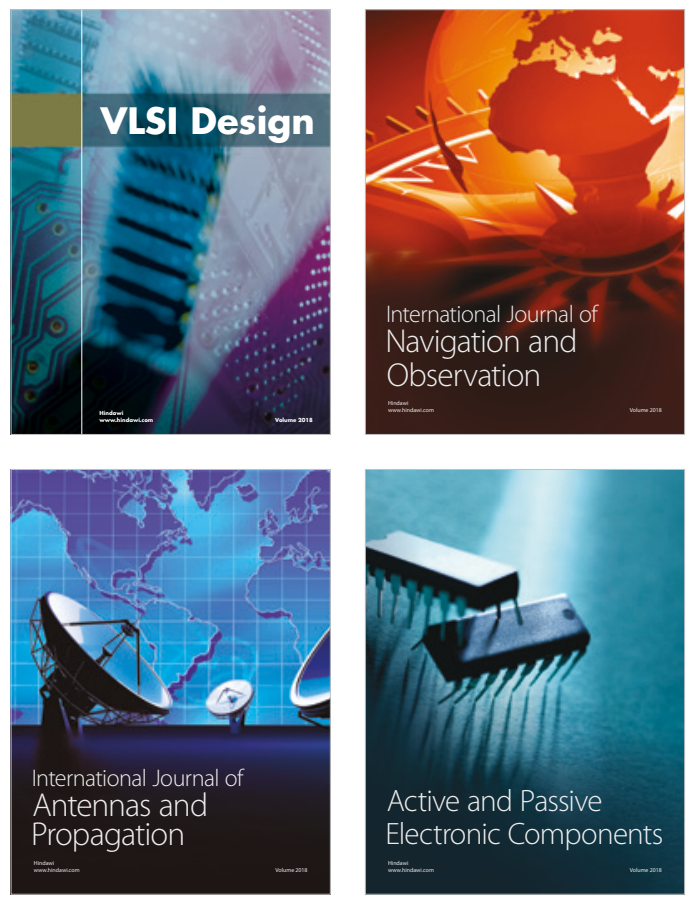
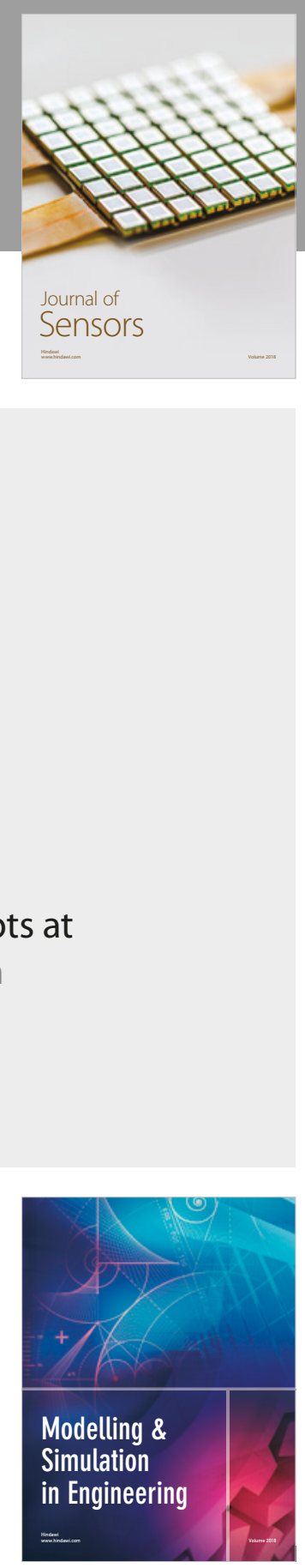

\section{Advances \\ Multimedia}
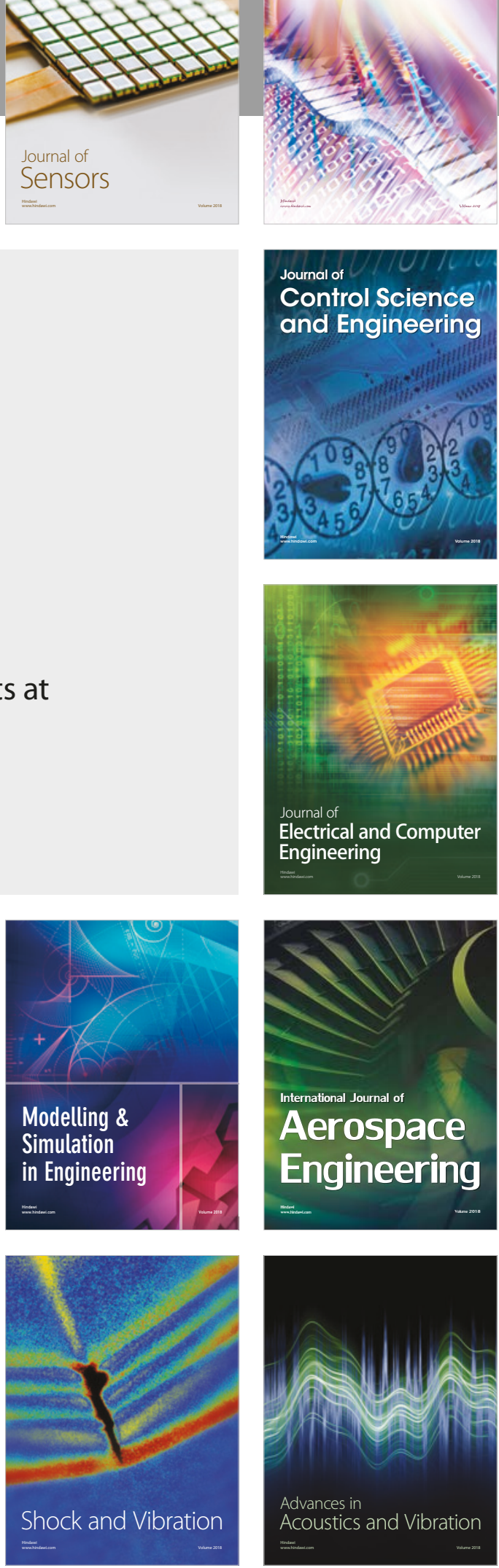